\title{
Papa Francisco y la economía civil: una vía para el bien común en la economía global
}

\section{Leonardo Becchetti' y Massimo Cermelli²}

Resumen: Un cambio en el estilo de vida puede ejercer una sana presión sobre aquellos que ostentan el poder político, económico y social. Es lo que ocurre cuando los movimientos de los consumidores logran modificar el comportamiento de las empresas, forzándolas a considerar el impacto ambiental y los modelos de producción.

"Comprar es siempre un acto moral, además de económico". Con estas palabras el papa Francisco subraya, en la última encíclica Laudato si", la relevancia del "voto col portafoglio" (el voto con la cartera), es decir, la importancia de las decisiones de consumo en la era de la economía global.

Tal y como se afirma en la encíclica Gaudium et Spes la economía, así como la vida socioeconómica deben estar al servicio del hombre y no al contrario.

La economía civil y el "voto col portafoglio" representan a día de hoy una trayectoria que desde la Gaudium et Spes a papa Francisco sugieren al hombre contemporáneo como gobernar la economía global a través del bien común.

Palabras clave: bien común, consumo, economía civil, eficacia, equidad, fraternidad, reduccionismo antropológico, "voto col portafoglio".

\footnotetext{
1 Università degli Studi di Roma "Tor Vergata", Roma. becchetti@economia.uniroma2.it

2 Universidad de Deusto - Deusto Business School, Bilbao. massimo.cermelli@deusto.es
} 


\section{Pope Francis and the civilian economy: one way for the common good in the global economy}

\begin{abstract}
A change in lifestyle can a healthy pressure on those who hold political, economic and social power. It is what happens when the movements of consumers manage to change the behavior of the businesses, forcing them to consider the environmental impact and the production models. "Buying is always a moral action, as well as economic". With these words Pope Francis underlines, in his last encyclical Laudato si', the relevance of the "voto col portafoglio" (voting with the wallet), i.e., the importance of the consumer decisions in the era of the global economy. As stated in the document Gaudium et spes the economy as well as the socio-economic life must be at the service of man and not vice versa. The "civil economy" ("economia civile") and the "voto col portafoglio" represent today a path from Gaudium et spes to Pope Francis suggests contemporary man as govern the global economy through the common good.
\end{abstract}

Keywords: good common, consumption, civil economy, efficiency, equity, fraternity, anthropological reductionism, "voto col portafoglio».

Recibido: 1 de septiembre de 2015.

\section{Le Pape François et l'économie civile: une manière pour le bien commun dans l'économie mondiale.}

Résumé: Un changement de vie peut une saine pression sur ceux qui détiennent le pouvoir politique, économique et social. C'est ce qui arrive quand les mouvements de consommateurs parviennent à modifier le comportement des entreprises, les obligeant à tenir compte de l'impact environnemental et les modèles de production. "Acheter est toujours un acte moral, aussi bien économique». Avec ces mots pape François souligne, dans sa dernière encyclique Laudato $s^{\prime}$, la pertinence du "voto col portafoglio» (droit de vote avec le portefeuille), c'est-à-dire, l'importance des décisions de consommation à l'ère de l'économie mondiale. Comme indiqué dans l'encyclique Gaudium et spes, l'économie, mais aussi la vie socioéconomique doit être au service de l'homme et pas l'autre. L'économie civile et «voto col portafoglio» représentent aujourd'hui une trajectoire qu'à partir de Gaudium et spes le pape François suggère l'homme contemporain comme gouverner l'économie mondiale par le biais du bien commun.

Mots clé: bien commun, consommation, économie civile, efficacité, équité, fraternité, réductionnisme anthropologique, "voto col portafoglio». 


\section{Introducción}

Es necesario meter de nuevo al centro la civis, la ciudad, en la cual se desenvuelve el mercado dirigiendo el mismo al originario lugar de intercambio donde la reciprocidad y el encuentro no suceden si no es a través de la presencia del ser humano. Esto es, en extrema síntesis, el tema clave de la economía civil: meter al hombre, la ciudad y la reciprocidad en el centro del debate, volviendo a considerar el mercado como el lugar en el cual estos tres aspectos se encuentran para buscar una armonía en la economía global.

La economía para ser armónica y equilibrada necesita de tres dimensiones: eficiencia, equidad y fraternidad, pero desafortunadamente cada etapa histórica tiene su lado corto/cojo que limita el potencial para crear las condiciones del bien común.

En los libros de economía actuales aprendemos, sobre todo, de eficiencia. Por tanto, ¿dónde situamos las dimensiones de equidad y fraternidad? ¿Cómo podemos afirmar, con la Gaudium et spes, que la economía, así como la vida socioeconómica, deben estar al servicio del hombre y no al contrario, sin tomar en consideración de forma contemporánea las tres dimensiones de la eficiencia, la equidad y la fraternidad?

El voto con il portafoglio y el redescubrimiento de una ciudadanía activa resultan aún más relevantes, a la luz de las exhortaciones de papa Francisco, para reconducir y gobernar la economía global después de la reciente crisis financiera, económica y social vivida en los últimos años. La crisis y la interdependencia de los problemas (económico, ambiental, financiero y antropológico) y su superación, a través del análisis de las causas de los tres reduccionismos (antropológico, empresa y valor), representan por otra parte una vía para el bien común en una época en la que la economía global dicta la agenda de la política internacional.

\section{El escenario de las cuatro crisis: de la mano invisible a los pianos}

Actualmente, es de sobra conocido que el escenario socio-económico en el que vivimos presenta diversas crisis o problemáticas estructurales interconectadas entre sí (crisis económica, financiera, ambiental y de felicidad o sentido de la vida) que se encuentran rigurosamente documentadas a través de numerosos datos.

El problema estructural de fondo de los sistemas económicos es la inmensa brecha en los estándares de vida en las diversas áreas del planeta que se traduce, 
asimismo, en otra grandísima brecha respecto de los costes de trabajo, a paridad de cualificación profesional, especialmente si atendemos a la situación de los trabajadores menos especializados.

Es posible verificar fácilmente estas desigualdades a través de los numerosos datos disponibles. El Bureau of Labour de los Estados Unidos documentó, en el año 201 1, una diferencia de alrededor de 30 a 1 en términos de costo promedio por hora antes de impuestos en el sector manufacturero entre Italia y países como India o China, si nos referimos al sector formal y llega hasta 60 si nos referimos al sector informal ${ }^{\prime}$. En economías cerradas el problema de la pobreza quedaba confinado al interno del área geográfica, y solo algún intelectual iluminado como John Rawls, basándose en los principios de bienestar y la sensibilidad de los misionarios, apoyaba con hechos el valor de ocuparse de "los últimos".

La globalización, rompiendo las barreras y moviéndose rápidamente hacia la creación de un mercado de trabajo y de bienes y servicios a nivel global, ha propiciado que esas enormes brechas que se mencionaban anteriormente se conviertan en un "boomerang" descargando las contradicciones sobre los propios países más ricos.

Como las empresas maximizadoras de beneficios buscan, en coherencia con sus objetivos, los costes de trabajo más bajos posibles, en los últimos decenios hemos asistido a un gigantesco proceso de deslocalización de la manufactura y no solamente en los países con bajos costes de trabajo. Este proceso nos "descuenta" el "pecado original" (por la parte de responsabilidad que nos toca) por haber creado bienestar y tutela en el trabajo para nosotros mismos pero no para el resto de los países y transforma la pobreza de esos otros países en una amenaza para nuestro propio bienestar. La globalización es, por tanto, una gran convulsión que hace que explote esa contradicción y que nos impide desentendernos de "los últimos". Hasta que este gigantesco ejército de reserva de mano de obra a bajo coste no sea absorbido las conquistas de nuestros trabajadores no podrán considerarse como seguras.

\footnotetext{
' La comparación se realiza sobre el denominado "hourly labour compensation cost", es decir sobre un coste de trabajo bruto que incluye, además del salario las contribuciones que la empresa paga al trabajador, aquellas que deposita directamente en el erario público y los impuestos relativos al trabajo pagados por cada hora de trabajo. Los últimos datos disponibles en lo que se refiere a China e India son 1,36 y 1,17 respectivamente para el sector formal, y en torno al 0,50 y 0,60 para el sector informal. El dato italiano es de 33,4 euros (U.S Bureau of Labour Statistics, 2011, Division of International Labor Comparisons www.bls.gov/ilcAnnual Labor Force Statistics, Adjusted to U.S. Concepts, 10 Countries, 1970-2010).
} 
No resulta casual que en todos estos años, desde el inicio de este gigantesco proceso, hayamos asistido a una progresiva erosión de tales conquistas y tutelas. $\mathrm{Si}$ en el periodo anterior a la globalización ocuparse de "los últimos" era una virtud de los misioneros, a día de hoy se ha convertido en una necesidad ineludible si queremos defender los niveles de bienestar adquiridos. En este sentido la globalización hace que "los últimos" se conviertan en nuestro próiimo y nos impide desinteresarnos de los mismos².

En una visión ultraliberal de laissez faire de la economía existe aún la tentación de afirmar que no es necesaria ninguna intervención porque existen mecanismos automáticos de reajuste que permiten, a largo plazo, que cada cosa vuelva a estar en el lugar que le corresponde. Las empresas deslocalizan, y en los países en los que la mano de obra cuesta poco, la demanda, mayor que la oferta, hace que los salarios se eleven de forma progresiva. Por otra parte, los trabajadores pobres, atraídos por el bienestar de los ricos, con los que se comparan de forma cada vez más opresiva gracias a la difusión de los medios de comunicación de masa y las redes, se sientes atraídos de forma irremediable a migrar hacia nuestros países transfiriendo de ese modo mayores ganancias en forma de remesas a sus países de origen.

Resulta innegable, para un observador atento, que existen al interno del sistema económico mecanismos que la Providencia ha puesto a disposición para poder alcanzar el bien común, mecanismos que dejan, a la vista del creyente que los observa, vislumbrar pistas de "algo" divino. El problema es que esos mecanismos necesitan de nuestra colaboración para la co-creación de un mundo más equitativo y sostenible. Usando una metáfora podemos decir que el sistema económico cuenta con numerosos pianos diseminados que pueden emitir armonías excepcionales, (pensemos también en el reciente flujo de las innovaciones ambientales que nace de la intuición de imitar la ecología de los ecosistemas en la creación de redes urbanas inteligentes que son capaces de gestionar de la mejor forma posible los recursos energéticos) pero nada puede suceder si no contamos con la presencia de músicos. En particular, y volviendo al problema de la brecha existente respecto de los costes de vida y trabajo, los mecanismos de reequilibrio, denominados auto-

\footnotetext{
2 Resulta evidente que los países con costes de trabajo más altos deben hacer todo aquello que se encuentre dentro de sus posibilidades para centrarse en otros factores competitivos (calidad del producto, de los servicios, productividad total de los factores, factores competitivos no deslocalizables tales como bienes históricos-culturales, paisajísticos, productos doc/dop, etc.). A pesar de todo ello es presumible que la persistencia del gap de los elevads costes de vida y de trabajo continuaran a hacer dificil la creación de valor económico en el territorio en las economías globalmente integradas.
} 
máticos, son excesivamente lentos y su funcionamiento depende, de modo crucial, de los comportamientos de los actores y de las reglas del juego. La metáfora del piano resulta por tanto más eficaz y adecuada que aquella que menciona la mano invisible. Como todos los economistas bien saben no existe una mano invisible que resuelve mecánicamente nuestros problemas transformando de forma mágica los egoísmos privados en el bienestar de toda la sociedad. Si resulta cierto que en unas determinadas condiciones, que prácticamente son irrealizables, en muchos sectores la competencia perfecta genera beneficios para los consumidores, la difundidísima presencia de externalidades negativas, bienes públicos, asimetrías informativas, tendencias monopolistas y oligopolistas de los sistemas abandonados a sí mismos, son elementos que llevan a otra dirección. Una visión más realista de la economía nos dice, por el contrario, que los pianos emiten sonidos en la medida en que los elementos mecánicos con los que han sido construidos son activados por actores socialmente responsables (empresas y ciudadanos) que son capaces de tener una visión a largo plazo.

Al problema económico de fondo, la inmensa brecha de los costes, se añade, y superpone, el problema ambiental. En extrema síntesis es prácticamente imposible que una población de más de 7.000 millones, que aún se encuentra en crecimiento, en un mundo con recursos ambientales de los cuales muchos son difícilmente renovables, o no renovables, pueda proveer a toda la población los niveles de bienestar de los países más ricos a través de los modelos de desarrollo utilizados antes de que explotase el problema ambiental en toda su gravedad. Una simple descomposición contable nos revela que el nivel de sustancias contaminantes agregado en un concreto ecosistema es producto de tres factores: población, producción (y consumo) "per cápita" y cantidad de contaminación por cada unidad producida (y consumida). Ello implica que la tan deseada reducción en el tiempo de las sustancias contaminantes podrá realizarse únicamente a través de tres vías (o una combinación de las tres): reducción de la población, reducción del producto (y consumo) "per cápita" y aumento de la eficiencia energética de la producción y del consumo.

También en este caso existen algunos pianos que no pueden emitir sonidos solos. Las mismas empresas maximizadoras de beneficios son conscientes de que el problema ambiental corre el riesgo de convertirse en algo más grave aún, aumentando de ese modo la sensibilidad de los ciudadanos. Invertir para innovar en este ámbito permitiría estar preparados ante la posible presencia de regulaciones más estrictas y generaría un flujo de innovación que posibilitaría, por sí mismo, el ahorro de energía ganando al mismo tiempo el favor de los ciudadanos más sensibles a esta cuestión. Se trata también en este caso de mecanismos que funcionan más 
rápidamente en presencia de regulaciones virtuosas y ciudadanos y empresas socialmente responsables.

El desafío ambiental nos induce también a modificar en profundidad nuestro concepto de bienestar reorientándonos, de forma natural, en direcciones más coherentes con estilos de vida más humanos y espirituales. Para vencer este desafío las actividades más inmateriales, sean capaces de generar rédito o no, son las más valiosas. Arte, filosofía, religión, sobriedad en el estilo de vida y de consumo o consumos colaborativos y participativos, a través de los cuales la comunidad aprende a compartir bienes reforzando sus redes relacionales, son vías preciosas para vencer este desafío que nos ayuda a tomar lo esencial. En particular el consumo colaborativo nos hace entender que aunque mantengamos el consumo de bienes y servicios, lo que verdaderamente importa no es la propiedad (que puede ser compartida) si no la fruición y el acceso, que puede ser participativo. ¿2Es realmente necesario que en un determinado barrio todos posean un bien de consumo que utilizan muy pocas veces? O quizás debemos movernos hacia el concepto de la "capacidad de consumo utilizada" tratando de intensificarla.

Actualmente, este desafío nos empuja a comprender mejor que la "riqueza de las naciones" no depende del flujo de los bienes y servicios producidos y facturados por unidad de tiempo. A pesar de que se trata de un factor importante, depende de forma sustancial de bienes y servicios no contabilizados porque han sido producidos por voluntarios, en el interior de las familias o por el stock de recursos económicos, naturales, culturales o religiosos que una comunidad tiene a su disposición. Por ello, el primer paso necesario para vencer este desafío es el de cambiar las "gafas estadísticas" con las que miramos la realidad.

La crisis financiera de la que son víctimas especialmente las economías occidentales es el resultado de estas dos problemáticas de fondo. La crisis ambiental impulsa la búsqueda de nuevas formas de creación de valor inmaterial que sean capaces de mantener los niveles de bienestar en un mundo dotado de recursos físicos difícilmente reproducibles. El esfuerzo prometeico de la finanza de multiplicar su capacidad de generar recursos de la nada ly creer haberlo conseguido creando en numerosas ocasiones burbujas que cuando explotan provocan un retroceso ruinoso) puede interpretarse desde la propia urgencia.

Las desigualdades entre ricos y pobres, que en la globalización se convierten en una amenaza para nuestro propio bienestar, erosionan de forma progresiva los salarios y el poder de adquisición de las clases medias-bajas en las economías ricas. El funcionamiento de las economías depende de los consumos masivos, pero en 
tales condiciones claudica. Así se puede verificar el imperativo de la imposibilidad de consumir más ganando menos, imperativo que únicamente puede resolverse a través de un endeudamiento creciente (público o privado).

Llegamos por tanto a la crisis financiera global cuyo punto álgido se ha registrado en septiembre de 2008, cuando se produjo la caída de una de las grandes bancas de inversiones americanas, Lehman Brothers. Las causas que han llevado al estallido de la crisis a día de hoy son de sobra conocidas. Numerosas crisis financieras nacen de un problema de "overlanding" (exceso de préstamos) y esta crisis no fue diferente. La anteriormente mencionada urgencia de gastar más ganando menos impulsó al sistema bancario americano a conceder préstamos a clientes que no se encontraban en situación de restituirlos, superando de forma más que amplía el límite prudencial que tradicionalmente se asumía entre el montante de la ratio a pagar y las cuotas mensuales. Los nuevos descubrimientos de la ingeniería financiera hicieron creer que esta situación podía llevarse a cabo sin que ello supusiese un aumento sustancial del riesgo para la banca prestamista si se realizaba a través del pasaje del modelo to hold al modelo to distribute. En el viejo modelo (originate to hold) el banco que presta sigue siendo responsable, razón por la cual tiene un gran interés en verificar la sostenibilidad del cliente. En el modelo originate to distribute la banca puede deshacerse del préstamo una vez que el mismo se haya realizado vendiéndolo a un intermediario financiero que se ocupa del proceso de titulización. Este intermediario financiero colecciona muchos préstamos similares (de alto riesgo), los mezcla con préstamos más seguros y genera nuevos activos financieros derivados (derivados el crédito), cuya sostenibilidad deriva de la sostenibilidad de los préstamos subyacentes recogidos. Estas actividades son, presumiblemente, de menor riesgo porque se aprovechan del principio de la diversificación entre préstamos de la misma y de diversa calidad.

Como los préstamos de alto riesgo poseen un riesgo de quiebra no correlacionado, - escasamente correlacionado entre ellos, no se producirá la quiebra de todos ellos al mismo tiempo y esto hace que el derivado del crédito tenga un menor riesgo. La falacia de este razonamiento es la chispa que hizo que explotase la crisis. En realidad la sostenibilidad de todos esos préstamos de alto riesgo dependía de un factor sistemático no diversificable que era el valor de los inmuebles, que se encontraban inmersos en una burbuja especulativa desde hacía mucho tiempo con el consecuente alto riesgo de colapso. Cuando dicho valor efectivamente se colapsa una gran parte de los prestatarios de riesgo (cuya solvencia dependía de las hipotecas de las casas que estaban adquiriendo o del valor de la parte ya adquirida al contado) se colapsan también provocando el colapso del valor de los derivados del crédito. Para comprender lo dramático de lo sucedido es necesario recordar que los activos de los mayores bancos internacionales habían sido 
inflados por el valor de los derivados, que aún hoy, a distancia de la crisis, valen menos del 10\% del precio de adquisición. Y en muchos estados (pueden tomarse en consideración a modo de ejemplo Islandia e Irlanda, aunque existen otros muchos casos) el valor de los activos bancarios eran varias veces superior al PIB del país ${ }^{3}$. El problema se agravó por la importante difusión de otra categoría de títulos derivados (los credit default swaps) es decir, los seguros adquiridos por los poseedores de los derivados del crédito como póliza en caso de que estos últimos colapsasen. Eran adquiridos a través de poquísimos intermediarios, siendo AIG el principal de todos ellos. Inmediatamente fue evidente que AIG, como asegurador, no podía hacer frente a la situación y cumplir con todos los contratos repagando a todos los poseedores de credit default swaps (sin valor alguno ya en este momento) generando de esa forma otra gran falla en el sistema.

Uno de los efectos más graves producidos de forma inmediata después de la caída de Lehman Brothers fue el riesgo de contraparte y la incertidumbre (hasta aquel momento se pensaba que los grandes bancos eran "demasiado grandes" como para dejarlos caer, por lo que en cualquier caso serían ayudados). La falta de transparencia en las cuentas bancarias y la dificultad para computar el peso de las sociedades vehículo que se encontraban ligadas a las principales pero no consolidadas en el balance, en el cual se anidaban gran parte de las operaciones con más riesgo, hizo que resultase muy difícil entender cuántos títulos tóxicos poseía cada banco entre sus activos. Todo ello hizo que se produjese una parálisis en el mercado interbancario, donde las instituciones bancarias intercambiaban liquidez entre ellas, paralizando de ese modo todo el sistema financiero y económico. Llegados a este punto la intervención de los bancos centrales y de los estados con medidas "electroshock" para reanimar la circulación financiera resultó imprescindible. Sin embargo, esta intervención supuso que un problema de deuda privada, de los bancos, se convirtiese en un problema de deuda de los estados, transfiriendo la carga del ajuste en su totalidad a las finanzas públicas. En términos cuantitativos, desde la explosión de la crisis hasta el momento actual se calcula que para salvar la banca, y el sistema, ha sido necesario utilizar una suma de dinero que oscila entre los 5 y los 15 billones de dólares si atendemos a como se computan las diversas inyecciones directas de capital en los bancos, la

\footnotetext{
${ }^{3}$ El total de los activos bancarios de los tres mayores bancos islandeses en el año 2008 representaban una cifra cercana a 9.8 veces el valor del PIB del país. En los Estados Únidos el valor representaba 1,2 veces el valor del PIB. En el caso de Islandia el crecimiento de esta cifra se había producido en los años inmediatamente precedentes a la crisis. En el 2003 los activos bancarios representaban solo el 1,7 veces el valor del PIB. En Irlanda los mismos activos bancarios crecieron del 1,8 en el 2003 al 3.8 en 2007 y los costes de la crisis para las finanzas públicas supusieron un valor cercano al $40 \%$ del PIB. Adalet McGowan, M. (2011).
} 
proporción de garantías o la compra de activos tóxicos por parte de los bancos centrales para retirar los mismos de los activos bancarios. Según los cálculos del Fondo Monetario Internacional ya a finales del 2009 habían sido gastados 7,1 billones de dólares. Para entender la envergadura de dichas cifras basta señalar que el total de la deuda italiana asciende a casi 1,9 billones de euros y que para financiar las obligaciones en el mundo bastaría con 10.000 millones al año, mientras que con una cifra que oscila entre los 36.000 y los 45.000 millones de dólares podría eliminarse la mortalidad infantil a lo largo del año 2015. Es evidente, por tanto, que vistas las dinámicas de la crisis, la responsabilidad de los diversos actores y las sucesivas intervenciones de salvación junto con la recaída de las consecuencias de los ajustes sobre los bienes y servicios públicos por parte de los estados, incluyendo aquellas partidas que hacían referencia a las personas más débiles, la crisis financiera ha supuesto un grave problema de equidad y de reparto de los costes del ajuste, poniendo además en clara evidencia la necesidad de una reforma urgente respecto de las reglas de los propios mercados financieros.

Debe remarcarse asimismo, que la situación post-crisis de los mercados financieros no parece que haya mejorado sustancialmente. La oleada de fusiones y concentraciones producida, que era necesaria para salvar e incorporar los grandes intermediarios que habían fracasado, ha provocado, de forma posterior, que el mercado se concentrase y como resultado puede apreciarse que actualmente, y respecto de años anteriores, son menos los operadores que controlan gran parte de la emisión de los derivados ${ }^{4}$.

Hemos estado acostumbrados a concebir los mercados financieros como lugares en los que una cantidad enorme y pulverizada de compradores y vendedores anónimos fijaban los precios. A día de hoy, sin embargo, de forma habitual leemos en la prensa financiera que los mismos precios bajan o suben únicamente porque uno de los mayores "players" ha decidido comprar. Aquello que llamábamos mercado no lo es más y son muchos los que hablan de los intereses de grandes grupos. Los verdaderos partidarios del mercado son aquellos que luchan, desde abajo, para aumentar la competencia y la democracia, como son los grupos de consumidores que se alían con los productores para competir con las grandes distribuidoras. Otro ejemplo de ello son todos aquellos que abren nuevos caminos para la inclusión y el acceso al mercado de "los últimos" a través de nuevas filiales solidarias y las

\footnotetext{
${ }^{4}$ Desafortunadamente debemos constatar que mientras que sumas ingentes de dinero han sido utilizadas, sin establecer condición alguna, para salvar los bancos, nuestra civilización no considera importante gastar sumas mucho menores para la consecución de otros objetivos mucho más importantes. Desde este punto de vista pueden apreciarse los datos que presentan BLUNDELL, A. y ATKINSON, P. (2010).
} 
microfinanzas. Realmente, el problema de los mercados financieros no es ya un problema de racionalidad y prepotencia de los más fuertes sino un problema de voluntad de poder que ha adquirido unas dimensiones incontrolables incluso para los propios actores. En la última, y gravísima, crisis financiera prácticamente todos los grandes actores habían fracasado y fueron salvados de forma incondicional ( $\sin$ establecer siquiera reglas para una futura estabilidad). Dentro de las mayores organizaciones no encontramos, por tanto, una racionalidad que se encuentre en grado de tutelar la propia supervivencia, sino únicamente un embrollo de intereses individuales (de "managers", grandes accionistas, "traders") que sobre la base de incentivos a corto plazo mal construidos ponen en peligro la supervivencia de las propias organizaciones. Desde este punto de vista, hasta que tales incentivos ("bonus", "stock options" sin sanciones en caso de pérdidas ("clawbacks"), indemnizaciones multimillonarias) sigan siendo instrumentos para remunerar a los beneficiarios en caso de éxito sin imponer sanción alguna en caso de fracaso, los actores seguirán incentivados a correr riesgos cada vez mayores con la certeza de que podrán descargar las eventuales pérdidas en la sociedad.

No es casual que en un sistema de este tipo, que escapa al control del hombre, que a los problemas económicos estructurales, la crisis ambiental y financiera se le superponga una gravísima crisis del sentido de la vida. Efectivamente, gran parte de la humanidad vive una condición laboral que es una dimensión constitutiva de su propio ser y siendo plenamente conscientes del profundo cisma existente entre sus ideales más profundos y la finalidad de muchas de las realidades laborales, sufre profundamente. Todo esto tiene consecuencias negativas relevantes respecto de la posibilidad de vivir plenamente la propia vida de relaciones y de fe porque estos vínculos descorazonan, empobrecen y reducen la libertad de movimiento y la disponibilidad del corazón que son necesarias para vivir la riqueza de una vida relacional y espiritual plena. Mientras que las vías de fuga de la indiferencia vienen anestesiadas por pequeños placeres $y$ transgresiones, que en realidad se han convertidos en nuevos conformismos.

El naufragio del sentido no es una invención porque ha sido constatado con datos y evidencias (y no solo con los datos, extremos, de la tasa de suicidios). En nuestro país, a lo largo del último decenio el consumo de antidepresivos se ha duplicado poniendo en evidencia la necesidad de apoyo artificial para vivir. 


\section{La superación de los reduccionismos: antropológico, empresa y valor}

La profunda raíz filosófica de las cuatro crisis se identifica con una matriz reduccionista del hombre, de la organización productiva y del concepto del valor. El reduccionismo antropológico recibe el nombre de "homo economicus". El hombre posee una dimensión cuya satisfacción dependería únicamente del crecimiento de los ingresos y del consumo, un modelo antropológico que se encuentra en la base de casi todos los modelos interpretativos de la realidad y que los propios economistas liberales critican, como por ejemplo Hayeck que admite que este homo oeconomicus es "la vergüenza de la familia" o Sen que lo denomina como "el loco racional" porque es una persona desprovista de dos componentes fundamentales de la naturaleza humana representados por el deber moral y la pasión por los otros.

Los resultados, a gran escala, de la economía experimental nos dicen que afortunadamente el hombre no es esto ${ }^{5}$, aunque corre el riesgo de serlo, porque la cultura reduccionista con su mirada descorazonadora trata de plasmar los objetos reduciéndolos a ser únicamente aquello que se ve. Decía Toniolo ${ }^{6}$ que

el interés personal ejercita una gran función en el magisterio de la vida individual y colectiva: en armonía con una de las leyes físicas supremas del universo, que representa la fuerza de gravedad del mundo moral, que no solo es condición y medio de equilibrio sino también uno de los elementos del progreso,

y resulta igualmente cierto, como nos recuerda Toniolo, considerando una análoga sugestión de Schumpeter, que la dictadura del autointerés acaba por alejarnos de la propia energía que hace que sea posible la existencia de grandes empresas en el ámbito económico, porque

la energía del trabajo, la virtud del ahorro, la idea de aquellas grandes empresas cuya duración supera la vida del individuo... repiten sobretodo el impulso de los afectos de la familia, del deseo de poner de manifiesto su importancia, de hacer crecer el decoro no solo desde el punto de vista de un simple cálculo de interés personal.

\footnotetext{
${ }^{5}$ ENGEL, F. (2010) en una revisión de los resultados de 328 diversos experimentos por un total de más de 28.000 observaciones calcula que solamente el $36 \%$ de los individuos se comporta como un homo oeconomicus, revelándose desprovisto totalmente de las actitudes pro-sociales. La cuota más alta es aquella relativa a los estudiavntes de las facultades de economía (en torno al $40 \%$ ) mientras que dicha tasa desciende sensiblemente en el colectivo de adultos y ancianos.

6 "Dell'elemento etico quale fattore intrinseco delle leggi economiche" del 5-XII-1873, Universidad de Padua
} 
Estas consideraciones han sido actualizadas y dotadas de un mayor significado a través de los recientes descubrimientos del pensamiento económico que admite que el centro de la vida económica está formado por dilemas sociales (dilema del prisionero, juegos de confianza, dilema del viajero) donde el capital social (confianza y merecimiento de confianza) es la savia fundamental que hace posible la vida económica misma, que en presencia de asimetrías informativas y el inevitable carácter incompleto de los contratos quedaría completamente paralizada por las interacciones entre los homines oeconomici ${ }^{7}$. Sin elementos de don, de gratuidad y de reciprocidad las interacciones económicas entre sujetos que no se conocen a fondo y que no pueden tutelarse con contratos que cubren cada posible eventualidad, resultarían, simplemente, imposible.

El reduccionismo en la concepción de la empresa es otro de los gravísimos problemas que nos encontramos. Puede captarse la gravedad del problema en su totalidad si se analizan las causas y las dinámicas de la crisis financiera. $\mathrm{Si}$ existen solamente empresas cuyo objetivo es la maximización de los beneficios se genera una escala de valores alterada en la cual la creación de valor para el accionista se convierte en el criterio al cual subordinar el bienestar del resto de los portadores de intereses influenciados por la vida de la empresa ("in primis" clientes, trabajadores, proveedores, comunidades locales del territorio en el cual la empresa opera y se encuentra localizada). Esa escala de valores alterada solo puede traer consigo consecuencias negativas cada vez que el interés del accionista entra en conflicto con valores superiores (como la tutela del trabajo o la salud de los clientes). La crisis nos demuestra que los intermediarios financieros orientados a la maximización del beneficio (a diferencia de los bancos éticos o las cooperativas) abandonan, de forma progresiva, su misión originaria de financiar con el crédito las inversiones de las empresas (reduciendo progresivamente la cuota de beneficios que derivan de tal actividad) cuando, tal y como sucede en nuestros días, el crédito se convierte en una "commodity" de escaso interés porque se trata de una actividad con bajos rendimientos y costes fijos elevados. Los intermediarios financieros reduccionistas que maximizan el beneficio, además de tener una gran

\footnotetext{
7 Una descripción intuitiva y fácilmente compresible de estos dilemas sociales de la parálisis de la confianza que bloquea la posibilidad creativa de la propia economía la encontramos en este apólogo de Hume que recita Tu grano está maduro hoy, el mío lo estará mañana. Resultaría util para ámbos si hoy yo trabajase para ti y tu mañana me dieses una mano a mi. Pero yo no percibo ningún particular sentimiento de benevolencia hacía tu persona y se que tu tampoco lo sientes por mi. Por tanto yo, hoy, non trabajare para ti porque no tengo garantía alguna de que tu, mañana demostraras gratitus hacia mi. Así te dejo trabajar hoy solo y mañana tu te comportarás de la misma forma conmigo. Pero llega el mal tiempo y siendo así acaba que ambos terminamos por perder la cosecha por falta de confianza recíproca y una garantía. HuME. D. (1740).
} 
responsabilidad en la generación de la crisis, representan justamente lo contrario de lo que ahora necesitamos para poder resolver las consecuencias de la crisis producida en la economía real, no existiendo bancos que posean la vocación de invertir recursos y energías en el territorio aun a costa de ganancias menos elevadas.

Finalmente el reduccionismo del concepto del valor nos recuerda que la búsqueda de indicadores cualitativos (desarrollo económico y social) por encima de los cuantitativos (crecimiento económico y producto interior bruto) marca la dirección hacia la cual queremos que se encamine nuestra sociedad. El largo debate sobre la oportunidad de utilizar determinados indicadores para medir la riqueza de las naciones en lugar de utilizar otros es cada vez más actual, y la necesidad de añadir la dimensión cualitativa, junto con la cuantitativa, a día de hoy parece que cobra más relevancia en el debate académico e institucional.

\section{Eficiencia, equidad y fraternidad.}

La economía para ser armónica y equilibrada necesita de tres dimensiones: eficiencia, equidad y fraternidad, pero a día de hoy, lamentablemente, cada etapa histórica tiene sus propias restricciones, que limitan el potencial para crear las condiciones del bien común.

En los libros de economía actuales aprendemos, fundamentalmente, la eficiencia. Conceptos como el "surplus" del consumidor y esquemas como la caja de Edgeworth nos explican, en modo claro, que el intercambio de mercado produce un aumento de la eficiencia generando en los contrayentes un nivel de satisfacción no inferior a aquel que sentían antes de llevar a cabo la transacción. Las elecciones de consumo de bienes por parte de los consumidores, de asunción de mano de obra por parte de la empresa y de asignación entre trabajo y tiempo libre por parte del individuo son considerados óptimos en base al principio de eficiencia, es decir la asignación óptima de los recursos escasos. En los mercados financieros las reglas se dirigen hacia la maximización de la eficiencia aumentando la liquidez y reduciendo los costes de transacción. Esta aproximación todavía soporta el impacto de un mundo donde el desafío principal es aumentar al máximo posible nuestra capacidad de producir bienes y servicios en ausencia de vínculos con los recursos naturales.

¿Y la equidad? Viene después. Una vez que hayan sido cubiertas las condiciones de eficiencia nos podemos preocupar de los que tienen más y de los que tienen menos y redistribuir parte de la riqueza. En cualquier caso la equidad es algo 
menos "cool" y parece que se trata de la excusa que esgrimen los holgazanes para quitar algo a las personas talentosas y meritocráticas que han creado riqueza, salvo por la particularidad de que los resultados dependen de las condiciones iniciales, que no son iguales para todos. Por ello el mérito de los meritocráticos no es todo merito suyo.

¿Y la fraternidad? Desaparecida del radar, lejos de la vista y confinada al ámbito más privado y al tiempo libre. Aunque también es cierto que a pesar de su invisibilidad, la fraternidad aparece como un elemento más "cool" y menos demodé que la equidad. En el famoso ciclo de vida del magnate americano sucede habitualmente que después de haber creado riqueza no existe la voluntad de morir rebosante de dinero y por ello una fundación se convierte en el instrumento idóneo para restituir dinero a la comunidad.

Todas las veces que alguno de los tres lados (eficiencia, equidad y fraternidad) se queda corto, el sistema se vuelve asfixiante.

Un mundo hecho solo con eficiencia se parece a ese modelo tantas veces promocionado por tantos colegas economistas, que casi sin darse cuenta se transforman en deshumanos sacerdotes de la diosa Eficiencia. Basta ocuparse de la eficiencia para producir, de modo óptimo, los recursos, y después, aun sin equidad y fraternidad, el sistema automáticamente hace que la riqueza gotee hacia abajo llegando por tanto a "los últimos". La teoría del "trickle down" se convierte así en la extrema justificación de un mundo creado solo con la eficiencia, sin equidad y sin fraternidad.

También la equidad sin eficiencia y fraternidad es deshumana. Las experiencias históricas a las que probablemente nos hemos acercado más han sido aquellas relativas al socialismo real. La igualdad en los resultados humilla el espíritu humano de emprendimiento. La equidad es fría e inhumana si no viene acompañada de la fraternidad y lleva al colapso económico si no presta suficiente atención al problema de la eficiencia.

Nosotros, los economistas civiles que apoyamos la fraternidad, no podemos dejar de reconocer que un mundo hecho solo con fraternidad, sin eficiencia y sin equidad es falso, ficticio y abre la puerta a todos esos fenómenos de nepotismo, clientelismo, mafia... en los cuales los intereses de los miembros del grupo, al que la persona se encuentra ligado por vínculos fraternales, se persiguen a expensas del bienestar de terceros. 
Pero si prestamos atención a un mundo hecho solo de eficiencia y equidad, admirablemente sintetizado a través del concepto de la igualdad de oportunidades y que parece ser el horizonte al que pretenden encaminarse muchos de nuestros colegas socialmente sensibles, es limitante y asfixiante. Mercado para la eficiencia es "welfare" para la equidad. Pero se trata, siempre y en todo caso, de un sistema en el que faltan reciprocidad, gratuidad e intercambio de dones que son el lubrificante fundamental para produciry poder disfrutar de unas relaciones sociales de calidad, que son el ingrediente esencial de la vida humana, y que a su vez alimentan ese capital social que es el adhesivo fundamental de cada sistema económico.

Solo por poner un ejemplo podemos pensar en la receta de "cero derroche-sprechi zero", iniciativa que se propone resolver, en términos logísticos, el problema del hambre en el mundo, trasfiriendo las sobras a aquellos que sufren el hambre. Posiblemente, desde un punto de vista meramente ingenierístico podría funcionar, pero ciertamente esta medida no produce dignidad ni permite el autodesarrollo.

Trabajar en el aspecto que se enfatiza de menos (aquel que queda más cojo) es la elección óptima para cada etapa histórica y para cada modelo. El socialismo real necesitaba de mayor eficiencia y fraternidad, la economía medieval, por el contrario, adolecía de eficiencia y equidad y la economía moderna de mercado precisa de una mayor fraternidad. Trabajar el aspecto que queda más desprotegido no es solo una obligación atribuida a los políticos y científicos sino que se trata de un deber que ocupa a los ciudadanos, que votando con la cartera ("voto col portafoglio") podemos hacer que venzan y prevalezcan en el mercado las empresas que son líderes en la capacidad de llevarnos hacia una sociedad armónica en grado de desarrollar una medida igual de las tres dimensiones.

\section{El “voto col portafoglio" y los nuevos "consum-actores"}

Frente a estas crisis estructurales y a estos macro-fenómenos, donde parecía que solo los grandes actores contaban, se presenta el riesgo de sentirse aplastados. Se trata de una sensación equivocada y con consecuencias negativas que mortifican nuestro sentido de la iniciativa, nuestro espíritu de libertad y el deber de esperanza. Los muros caen en cuestión de segundos y en un momento todo puede cambiar rápidamente si así lo deseamos y entendemos, con inteligencia, cual es la vía más eficaz para actuar. Los mercados somos nosotros, o dicho de otra forma, los mercados están compuestos por la oferta y la demanda, y en uno de los dos lados siempre nos encontramos con ciudadanos que consumen y ahorran. 
Existe por tanto una solución huevo de Colon que es capaz de resolver los problemas que hemos mencionado previamente y es el "voto col portafoglio". Esto es, la decisión de premiar con el propio consumo y ahorro a aquellas empresas socialmente responsables y eficientes en las tres dimensiones, que se revelan particularmente capaces de internalizar el problema de creación de valor económico socialmente y ambientalmente responsable, que resulta vital para salir de las cuatro crisis. $\mathrm{Si}$ los ciudadanos toman conciencia del hecho de que sus elecciones de consumo y ahorro son actos políticos a través de los cuales expresan su agrado respecto de las empresas que venden sus productos, el mundo podría cambiar. Es necesario señalar que enfatizando la importancia y el papel del "voto col portafoglio" en los sistemas económicos contemporáneos, no se pretende, de ninguna manera, devaluar o restar importancia a los instrumentos tradicionales de participación política (como el voto electoral, el referéndum o la actividad política tradicional). Al contrario, partiendo de la observación desencantada de la realidad, algunos consideran que la política se encuentra subordinada a la economía y a su vez la economía está subordinada a las finanzas, para descubrir que la urna más importante en la cual puede ejercitarse nuestro derecho al voto, cada día y no cada cuatro años, es el propio consumo y ahorro responsable. Desde este punto de vista el "voto col portafoglio" y la buena política son complementarias y no sustitutivos, y a través de la sociedad civil y los representantes iluminados de las instituciones pueden ayudarse a alcanzar juntos el objetivo del bien común.

Si para ser luz en el mundo basta la gesta de algunos grandes santos o héroes aislados, para provocar una transformación política virtuosa y duradera, que actúe como levadura al interno de una sociedad, necesitamos de gestos coordinados y continuados de una mayoría de personas de buena voluntad $y$, por tanto, de estrategias o propuestas que no exijan de niveles muy elevados de altruismo de tal modo que puedan ser secundadas por grandes masas. Y esta es una de las ventajas del "voto col portafoglio", que para su activación no precisa de una condición de socialidad particularmente fuerte, bastando con una forma de autointerés con visión a largo plazo. Cuando un consumidor/ahorrador escoge un bien o un servicio de una empresa a la vanguardia en la sostenibilidad ambiental está reduciendo para sí mismo y para la sociedad las consecuencias negativas de la insostenibilidad, como son la contaminación, las enfermedades, el calentamiento global, etc. Cuando se escoge un bien o un servicio producido por una empresa a la vanguardia en sostenibilidad social se está premiando una sociedad que tutela los derechos del trabajo, lanzando al mercado y a las otras empresas una señal de estímulo para proceder en esa misma dirección, con los posibles beneficios que al mismo tiempo puede reportar al trabajador. 
Llegados a este punto la objeción más común es que el "voto col portafoglio" en el fondo es un voto de "casta" (solo pueden ejercitarlo aquellas personas que disponen de recursos), ya que en numerosas ocasiones esta elección exige un plus de recursos económicos que muchos ciudadanos no pueden permitirse.

Evidencias empíricas a gran escala respecto de los hábitos de los consumidores demuestran que el consumo es un acto profundamente simbólico a través del cual las personas satisfacen necesidades complejas (de estatus, de exclusividad, de sociabilidad o de conformidad con ciertos grupos de referencia) yendo más allá de la búsqueda del precio mínimo. Si nos centramos en el ámbito específico de la responsabilidad ambiental, existen evidencias consolidadas que demuestran que un tercio de la población estaría dispuesto a pagar más por las características socioambiéntales del producto y casi la totalidad de los ciudadanos prefiere un producto "ético". Ese tercio de la población de la que hablamos resulta más que suficiente para generar enormes procesos de contagio y de transformación que permitan orientar los sistemas económicos a la búsqueda del bien común.

El autointerés con vistas al futuro del "voto col portafoglio" está construyendo y construirá progresivamente una sociedad más empática, sostenible y participativa, pero para poder llegar a este objetivo los consumidores deben crecer con la conciencia de la importancia de sus propias decisiones, mientras que del lado de la oferta es necesario organizar, de la mejor manera posible, las condiciones que facilitan el "voto col portafoglio". La conciencia de los consumidores podrá madurar si ellos mismos, hasta el final, perciben y acogen la potencialidad de contagio que ofrecen los pequeños gestos al interno del sistema. Las evidencias empíricas de los últimos años demuestran que la alianza inicial entre las empresas pioneras (dedicadas al $100 \%$ a la sostenibilidad social y ambiental) y los ciudadanos que votan "col portafoglio" ha provocado, que de forma progresiva, emerjan pequeñas cuotas de mercado que contradecían, con hechos, los dos siguientes reduccionismos: el reduccionismo antropológico y el reduccionismo de empresa (si todos somos homo economicus y existen o sobreviven solo empresas maximizadoras de beneficios, tales cuotas de mercado no pueden existir). El efecto más importante de esas cuotas de mercado ha sido el de generar procesos de contagio que a su vez han generado un proceso de imitación por parte de otras empresa tradicionalmente maximizadoras de beneficios.

Estas empresas ante el descubrimiento de la invalidez de los reduccionismos, han constatado que la respuesta óptima, coherente con su objetivo de maximización de beneficios, era imitar parcialmente los pioneros introduciendo entre la gama de sus productos algunos social y ambientalmente responsables. Todo ello ha 
generado lo que se ha venido a denominar como mainstreaming de la responsabilidad social, que comienza a ser evidente en nuestros días 8 . Por ejemplo hay sectores específicos en los que los productos ecosolidarios han entrado de forma abrumadora conquistando en algunos casos cuotas de mercado notables. Un ejemplo de todo ello viene representado por el caso de las bananas en el Reino Unido, que han sido elegidas como producto símbolo de las más importantes cadenas de distribución tradicionales (Tesco y Sainsbury). Con el resultado de que, a día de hoy, esas grandes cadenas venden exclusivamente, o prevalentemente, bananas ecosolidarias que han conquistado rápidamente un $25 \%$ de la cuota de mercado global nacional. El "mainstreaming" presenta como obvios aspectos controvertidos. Eso genera una cierta crisis entre los pioneros que se encuentran con que deben competir con los colosos del sector, que gracias a las economías de escala pueden hacer "dumping" social y vender el producto ecosolidario a un precio más bajo. Llegados a este punto, los pioneros para poder competir no pueden centrarse en la diferencia relativa al producto sino que deben concentrarse en la verdadera ventaja competitiva que poseen, que es su dedicación, al 100\%, a la causa de la responsabilidad social, una ventaja que si bien la empresa maximizadora de beneficios imita parcialmente, no podrá copiar nunca. Esta ventaja competitiva es "ya y no todavía", puesto que en parte se está llevado a cabo, pero en parte aun cuenta con una potencialidad futura a desarrollar. Los pioneros pueden, efectivamente, prometer que una vez que hayan crecido hasta alcanzar el tamaño de sus actuales competidores, esto es, las empresas maximizadoras del beneficio, dedicaran más recursos y energía al objetivo de la responsabilidad socioambiental, como algo implícito a su "governance", sus objetivos y los principios estatutarios. Un aspecto controvertido, pero importante, del "mainstreaming" es que ayuda a crecer en modo imponente el conocimiento y los hábitos de adquisición de los productos socialmente responsables respecto del gran público. Los análisis de mercado del Reino Unido documentaban que frente a un tercio de ciudadanos sensibles, que estaban dispuestos a pagar por los contenidos de responsabilidad socioambiental de los productos, existía una masa de dos tercios que seguían servilmente los hábitos de consumo de las marcas. En el momento en el que las grandes marcas comienzan a vender productos de marca ecosolidarios también esos dos tercios de consumidores comienzan a adquirir dichos productos y sobre todo, gracias a

\footnotetext{
${ }^{8}$ Según KPMG (2005) el 90\% de las empresas japonesas, el 71\% de las empresas de Reino Unido y el $32 \%$ de las empresas estadounidenses cuentan con un presupuesto social. En el 2010 el ICCA Global Report Survey (2010) muestra que el 31\% de las empresas que se enceuntran entre las 500 primeras del mundo, según Fortune poseen un departamente separado de responsbailidad social de la empresa. El Global Consumer Report de Nielsen (2012) documenta que el $46 \%$ de la muestra de ciudadanos intrevistados se encuentra dispuesto a pagar más por productos socialmente y ambientalmente responsables.
} 
la inversión en marketing de los imitadores parciales se da a conocer la economía solidaria y la potencialidad del "voto col portafoglio".

Volviendo al cuadro de referencia con el cual empezábamos, esto es, la brecha existente en los costes de vida y de trabajo en las diversas áreas del planeta (véase nota uno), observamos que el "voto col portafoglio" representa una estrategia en la dirección correcta para afrontar esas desigualdades. No se trata de una reacción proteccionista, un portazo a "los últimos" o un simple aprovechamiento de las ventajas de precio ofrecidas al consumidor por la diversidad de los costes de trabajo gracias a la deslocalización productiva. Se trata de estimular un reequilibrio, hacía arriba, lo más rápido posible, de esas brechas premiando aquellas empresas que más rápidamente transfieren las tutelas y los derechos a los trabajadores más desheredados. Si queremos atacar el problema más importante (la inmensa brecha creada entre los diversos coste de vida y de trabajo en las diferentes áreas del planeta) que se encuentra en la raíz de las cuatro crisis, necesitamos urgentemente el "voto col portafoglio".

Es necesario poner en evidencia que la Iglesia Católica, en su más reciente reflexión sobre la Doctrina Social de la Iglesia, ha reconocido plenamente el valor del "voto col portafoglio", y lo ha puesto en práctica en diversas ocasiones a través de organizaciones de inspiración eclesiástica y religiosa, reconociendo su importancia estratégica y su profunda coherencia con las aspiraciones del estilo de vida cristiana, inspiradas por el Evangelio, que desde la óptica de una plena encarnación revindican que la dimensión económica y social no quede al margen de la vida cristiana.

\footnotetext{
"Un importante reconocimiento a la capacidad de contagio del "voto col portafoglio" vino por parte de la Comisión UE, que en el año 2009 afirmó a proposito del comercio equitativo y solidario (uno de los ámbitos con más exito) que "el comercio equitativo y solidario ha jugado un papel pionero a la hora de iluminar cuestiones de responsabilidad y solidaridad, impactando de esa manera en otros operadores y estimulando la creación de otros regimenes de sostenibilidad. Iniciativas privadas sobre la sostenibilidad, ligadas al comercio, utilizan a día de hoy varios standares de sostenibilidad social y ambiental que han crecido en numero y cuota de mercado.
} 
Los principios del "voto col portafoglio" son, efectivamente, citados en el Compendio de la Doctrina Social de la Iglesia ${ }^{10}$ y posteriormente mencionados en dos pasajes de Caritas in Veritate ${ }^{11}$.

También hay que destacar como de este principio, y del acento que pone sobre la promoción de los pioneros, emerge una profundización del propio concepto de "caritas" en el comercio ecosolidario, la banca ética y las microfinanzas. La "caritas" o la ayuda a "los últimos" no se considera un óbolo que mantiene las distancias sino un estímulo a la inclusión y a la laboriosidad que pide corresponsabilidad y respuesta ofreciendo a cambio dignidad. Si en la óptica de Caritas in Veritate la "caritas" debe encontrar su correspectivo en la "veritas" de la naturaleza humana, y si esa "veritas" es la antropología del don y de la relación a imagen y semejanza divina, se hace bien al pobre si se le facilitan las condiciones necesarias para la realización plena de su naturaleza humana. Es decir, si se encuentra en condiciones de dar y de donar, reintegrándole plenamente en sus derechos y deberes, ofreciéndole un papel activo en la sociedad.

El "voto col portafoglio" representa, por tanto, un aspecto importante de la encarnación. Si la encarnación es un aparente oxímoron (un Dios que se hace hombre), también en economía el progreso llega a través de aparentes oxímoron (comercio equitativo, finanzas y banca ética, economía de comunión) en los cuales el plan

\footnotetext{
${ }^{10}$ La utilización del propio poder adquisitivo debe ejercitarse en el contexto de las exigencias morales de la justicia y de la solidaridad, y de responsabilidades sociales precisas: no se debe olvidar "el deber de la caridad, esto es, el deber de ayudar con lo propio "superfluo" y, a veces, incluso con lo propio "necesario", para dar al pobre lo indispensable para vivir». 745. Esta responsabilidad confiere a los consumidores la posibilidad de orientar, gracias a la mayor circulación de las informaciones, el comportamiento de los productores, mediante la decisión-individual o colectiva-de preferir los productos de unas empresas en vez de otras, teniendo en cuenta no sólo los precios y la calidad de los productos, sino también la existencia de condiciones correctas de trabajo en las empresas, el empeño por tutelar el ambiente natural que las circunda. Compendio de la Doctrina Social de la Iglesia, n. 359.

1 Es necesario un cambio efectivo de mentalidad que nos lleve a adoptar nuevos estilos de vida, a tenor de los cuales la búsqueda de la verdad, de la belleza y del bien, así como la comunión con los demás hombres para un crecimiento común sean los elementos que determinen las opciones del consumo, de los ahorros y de las inversiones Caritas in Veritate n. 51 y La interrelación mundial ha hecho surgir un nuevo poder político, el de los consumidores y sus asociaciones. Es un fenómeno en el que se debe profundizar, pues contiene elementos positivos que hay que fomentar, como también excesos que se han de evitar. Es bueno que las personas se den cuenta de que comprar es siempre un acto moral, y no sólo económico. El consumidor tiene una responsabilidad social especíica, que se añade a la responsabilidad social de la empresa. Los consumidores deben ser constantemente educados para el papel que ejercen diariamente y que pueden desempeñar respetando los principios morales, sin que disminuya la racionalidad económica intrínseca en el acto de comprar. Caritas in Veritate n. 66.
} 
ideal en lugar de quedar separado del "business as usual" se encarna en el mismo fecundándolo y transformándolo, desde dentro, convirtiéndose en pan partido dentro de los bienes y servicios que son el fruto de la actividad económica ordinaria.

\section{Bibliografía}

BECCHETTI, L. y CIAMPOL, N. (2012), What is new in the finance-growth nexus: OTC derivatives, bank assets and growth, mimeo.

BeCCHetTI, L. y Cermell, M. (2014), "Reduccionismos económicos y "voto con la cartera", Revista de Fomento Social 69, 121-135.

Blundel-WIGNALl, A. y AtKINSON, P. (2010), "Global SIFls, Derivatives and Financial Stability", OECD Journal: Financial Market Trends 1.

Encíclica Caritas in Veritate (29 de junio del 2009).

Constitución pastoral Gaudium et Spes (7 de diciembre de 1965).

Mannaro, K., Marchesi, M. y Setzu, A. (2008), "Using an artificial financial market for assessing the impact of Tobin-like transaction taxes," Journal of Economic Behavior \& Organization, 67 (2), 445-462.

MAtheson, T. (2011) "Taxing Financial Transactions. Issues and Evidence", IMF Working Paper n. 11/54, marzo, 8.

PeluzZarl, P. y Westerhoff, F. (2009)," Some effects of transaction taxes under different microstructures" Journal of Economic Behavior \& Organisation, 72 (3), diciembre, 850-863).

Pontificia Comisión Justicia y Paz (2005), Compendio de Doctrina social de la Iglesia, Roma, Libreria vaticana.

Rousseau, P. y Wachtel, P. (2009) "What is happening to the impact of financial deepening on economic growth?": Economic Inquiry 48, DOI:10.1111/j.1465-7295.2009.00197.x

Toniolo, G. (1873), Dell 'elemento ético quale fattore intrinseco delle leggi economiche, Padua Università.

U.S. BuREAU OF LABOR Statistics (2011), Division of International Labor Comparisons Annual Labor Force Statistics, Adjusted to U.S. Concepts, 10 Countries, 1970-2010, 30, marzo. www.bls.gov/ilc. 